ages of health workers. In response, the WHO last week launched a new plan, entitled "Treat, Train, Retain." Meanwhile, disturbing new research revealed that since 2000 , infection rates in Uganda - long touted as a leader in tackling the epidemic - have either plateaued or even increased after years of significant annual declines.

While the rallying cry "universal access to treatment" was oft-heard at the conference, the slogan was oftmodified to emphasize universal access to "prevention, treatment and care." Half of new HIV/AIDS infections are among I5-24-year-olds, yet few prevention or treatment programs target the age group and most donors object to treatment literacy initiatives that help people understand either the nature of the disease or its treatments, said South African activist Gregg Gonsalves.

Just a decade ago, the cost of frontline AIDS treatments averaged \$20 ooo per patient year, clearly prohibitive for the developing world. Thanks to AIDS activists and agencies like UNAIDS and the Clinton Foundation that have worked with brand name and generic drug companies, that's now hovering at about \$I50/year. Some Io pills/day were once the norm. That's now down to 3 and the US Food and Drug Administration recently approved a I-a-day formulation. But about 10\% of treatment recipients will develop drug resistance by 2010, which has major cost implications as second-line therapies in developing countries typically cost Io times more.

Yet, the HIV/AIDS pandemic is more just a medical, scientific and economic challenge, incoming president of the International AIDS Society president, Dr. Pedro Cahn, told the largest and most diverse conference devoted to a global health issue. "Poverty is the driving force of this epidemic," while the spread of the virus continues to be linked to stigma and discrimination. When 3 members of the Blue Diamond Society in Nepal died of AIDS, families wouldn't claim the bodies and no ambulance would pick them up for transport to the crematorium. "We had to carry the bodies ourselves," said Suni Babu Pant, co-founder of the society for lesbian, gay and transgendered Nepalis.

Piot argued such stigmatization must end. "We need to get serious about protecting human rights. If we don't advance social justice as we advance science, we are doomed to failure." - Ann Silversides, Toronto

DOI:Io.I503/cmaj.o6rogo

\section{MED-1: Hospital on wheels}

$\mathrm{E}$ arlier this year, a New Orleans blogger noted on his Web site that a mobile hospital deployed to Mississippi last September to care for victims of Hurricane Katrina was now en route to New Orleans for Mardi Gras.

"Does that mean they are planning for Mardi Gras to be a disaster?" he asked.

Not quite. North Carolina's MED-I, a one-of-a-kind hospital on wheels, was sent to New Orleans at the request of the US government to boost the number of hospital beds available during Mardi Gras, when the population of the devastated city was expected to swell temporarily.

Last fall, after Katrina slammed into the Gulf Coast, MED-I — an acronym for Medical Emergency Department treated 7500 patients on its debut mission to Waveland, Miss. One of the few success stories in the bungled response to the deadly storm, MED-I took over for area hospitals knocked out by Katrina's floodwaters and violent winds.

MED-I began as the brainchild of Dr. Tom Blackwell, medical director for the Center for Prehospital Medicine at Carolinas Medical Center in Charlotte, NC, who set out in 2000 to create a mobile hospital sophisticated enough to serve areas paralyzed by terrorist attack or natural disaster.

The US Department of Health and Human Services and several other nations' governments have expressed interest in purchasing a MED-I.

Blackwell's self-contained hospital, built over several years at a cost of \$I.5 million to the US Department of Homeland Security, fits into 2 standard-size tractor trailers. Slide-out walls expand I trailer into a 90-squaremeter hospital that includes 7 general care beds, 4 critical care beds, a dental chair and a 2-bed operating room.

The unit, which is self-sustaining for 48 hours, has complete lab, radiology, ultrasound and pharmacy facilities, and satellite communications for off-site consulting.

A special filtration system allows MED-I to operate in biologically hazardous conditions. An attached air-conditioned tent, carried in the support truck, accommodates 88 additional cots.

Designed for speedy, I-hour setup, MED-I can handle a wide range of medical and dental emergencies, including cardiac arrest, orthopedic sta-

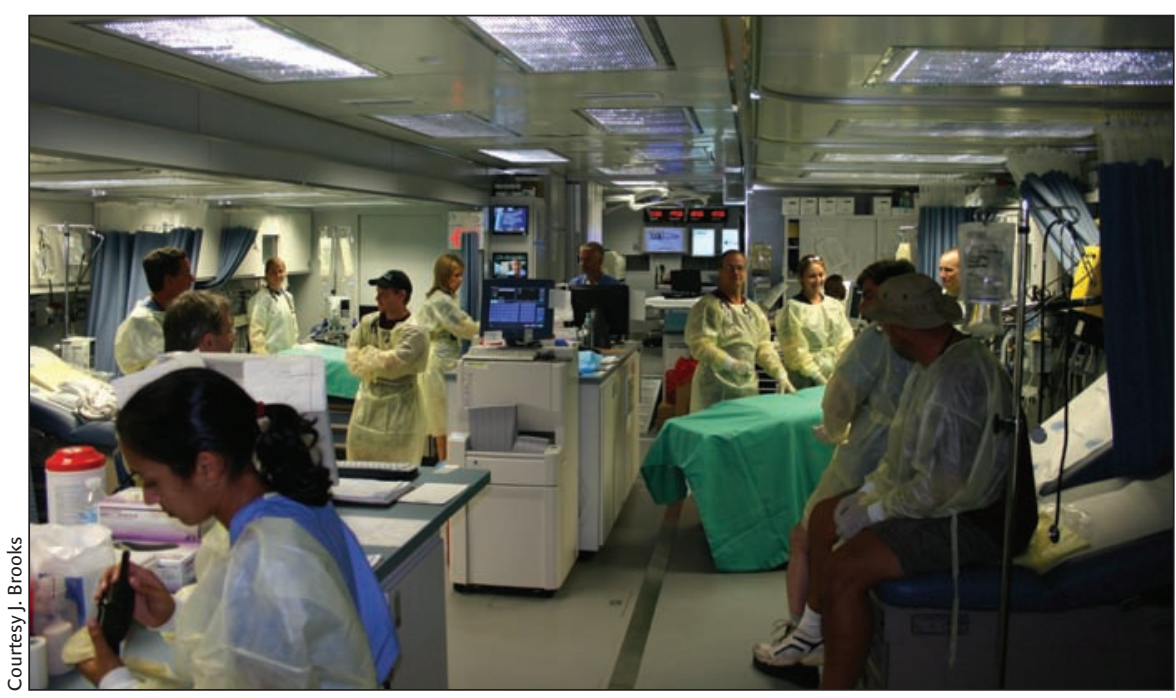

Medical staff prepare for patients inside the mobile hospital. 
bilization, burn treatment, wound repair, and management of multiple medical problems.

To Blackwell's knowledge, it is the first full-scale hospital treatment facility on wheels. "We call it the ultimate house call," he says.

MED-I was awaiting its first field test when Katrina struck last Aug. 29. Just 5 days later, it left Charlotte, NC, for the Gulf Coast.

The volunteer staff of more than 80 doctors, nurses, paramedics and support personnel cleared trees and other debris from a Waveland Kmart parking lot, and got to work for the next 7 weeks.

Initially, patients had cuts from storm debris, and rashes and skin infections from wading through contaminated floodwaters. The staff also treated car-crash victims and provided followup care to patients who had recently undergone surgery. But the seriously ill patients they expected didn't turn up. Finally, they realized that perhaps many diabetics and cardiac patients hadn't survived without their medications.

The rotating staff, drawn from North Carolina hospitals and trauma centres, slept on cots, and initially took cold showers and lived on ready-to-eat meals.

But there was an upside: "We got back to old fashioned medicine touching people, talking to people, spending more time at patients' beds," says Blackwell. "It was life-changing. People begged to come back."

Six months later, a crew of 15 did return to the Gulf Coast to back up New Orleans' gutted hospital system during Mardi Gras. The city had lost nearly twothirds of its hospital beds and had just 2 functioning emergency departments.

MED-I pulled into a parking lot near the Superdome late one evening and, with the help of more than a dozen local healthcare workers, it was ready to receive patients the next morning. At the time, only 4 hospital beds were free in the city. It stayed 2 weeks.

The blogger who had wondered if officials were expecting a Mardi Gras disaster added a final comment. "At least," he wrote, "they are planning." If he only knew. - Janet Brooks, Salt Lake City, Utah

\section{West Nile virus still a threat}

I t's tempting to conclude that the worst is over, that precautionary measures and the vicissitudes of fate and nature have somehow combined to reduce the health threat posed by the West Nile virus (WNV).

But experts say the lower incidence as of Aug. I2, 2006 (Table I) is hardly an indicator that WNV has been contained, or even a sign that the ultimate incidence will be lower because the WNV season peaks from mid-August through September.

In fact, there's a good possibility WNV rates in Manitoba and Saskatchewan will soon soar as a species of mosquito called Culex tarsalas, a vigorous biter that loves to breed in sun-dried prairie ditches, appears more prevalent this year and "its infectivity rate is up," says Mike Drebot, head of Health Canada's Viral Zoonoses Section.

"The dry hot summer actually can be conducive for more generations of mosquitos and hence, a greater possibility that we're going to get infected mosquitos. And, also, the virus replicates within the mosquito at a higher rate when it's hotter."

The vectors and variables that affect $\mathrm{WNV}$ rates are too poorly understood to safely say the threat is dissipating, adds Drebot. One variable is the fact that birds carrying the virus are becoming "more immune as a population," Drebot says.

But speaking on behalf of the Association of Medical Microbiology and Infectious Disease Canada, Neil Rau says it also appears there's genetic transmission of West Nile within mosquito larvae, "a sort of over-wintering mechanism," so the spread of the virus isn't limited by annual reintroduction from migratory birds.

"It's here to stay and one of the concerns about West Nile is that it does seem to infect numerous different species of mosquitos unlike the old St. Louis Encephalitis virus [which afflicted about 2500 people in North America in the mid I970s]. This means that WNV has a much larger environmental niche in terms of mosquito species and a much greater geographic distribution," adds Rau, the medical director of infection, prevention and control for Halton Health Care Services in Ontario. "It also seems very hardy, in that it can tolerate continental climates that are quite north."

The experts concede this year's lower incidence may be partially attributable to mosquito abatement programs, particularly in large urban cen-

Table 1: Number of human cases of West Nile virus infection in Canada, 2002-2006

\begin{tabular}{lccccc}
\hline & \multicolumn{5}{c}{ No. of reported cases } \\
\cline { 2 - 6 } Province/territory & 2002 & 2003 & 2004 & 2005 & $2006 \dagger$ \\
\hline Newfoundland and Labrador & 0 & 0 & 0 & 0 & 0 \\
Prince Edward Island & 0 & 0 & 0 & $1^{*}$ & 0 \\
Nova Scotia & 0 & $2^{*}$ & 0 & $1^{*}$ & 0 \\
New Brunswick & 0 & $1^{*}$ & 0 & $1^{*}$ & 0 \\
Quebec & 20 & 17 & 3 & 6 & 0 \\
Ontario & 394 & 89 & 14 & 101 & 0 \\
Manitoba & 0 & 142 & 3 & 58 & 10 \\
Saskatchewan & 0 & 947 & 5 & 58 & 0 \\
Alberta & 2 & 275 & 1 & 10 & 0 \\
British Columbia & 0 & $20^{*}$ & 0 & 0 & 0 \\
Yukon Territory & 0 & $1^{*}$ & 0 & 0 & 0 \\
Northwest Territories & 0 & 0 & 0 & 0 & 0 \\
\hline Nunavut & 0 & 0 & 0 & 0 & 0 \\
\hline Total (no. of deaths) & $416(20)$ & $1494(14)$ & $26(2)$ & $236(12)$ & $10(0)$ \\
\hline Rerayyyyyy
\end{tabular}

*Related to travel outside the province/territory.

†As of 2006 Aug. 12. 